\title{
COMPARATIVE STUDY OF MEDICAL AND CONSERVATIVE SURGICAL METHODS FOR UNRUPTURED ECTOPIC PREGNANCIES
}

\author{
Y. Padma1, Garuda Lakshmi2, Kambham Suhasini ${ }^{3}$, Swathi $K^{4}$, Purushotham ${ }^{5}$
}

${ }_{1}^{1}$ Associate Professor, Department of Obstetrics \& Gynaecology, Kakatiya Medical College, Warangal, Telangana. ${ }^{2}$ Associate Professor, Department of Obstetrics \& Gynaecology, Kakatiya Medical College, Warangal, Telangana. ${ }^{3}$ Associate Professor, Department of Obstetrics \& Gynaecology, Kakatiya Medical College, Warangal, Telangana. ${ }^{4}$ Post Graduate, Department of Obstetrics \& Gynaecology, Kakatiya Medical College, Warangal, Telangana. ${ }_{5}^{5}$ Assistant Professor, Department of Obstetrics \& Gynaecology, Kakatiya Medical College, Warangal, Telangana.

\section{ABSTRACT}

\section{AIMS AND OBJECTIVES}

To study and compare medical (Methotrexate) versus surgical (Laparoscopic salpingostomy) conservative management for unruptured ectopic pregnancy.

\section{MATERIALS AND METHODS}

This is a prospective study conducted at CKM Government Maternity Hospital, Warangal, Telangana. The recruitment period was from July 2012 to June 2013 and these patients were followed for 2 years from July 2013 to June 2015. An institutional ethical clearance was obtained and an informed consent was taken from the patients who were selected for the study. Of the 63 unruptured ectopic pregnancy cases, 31 patients were given multiple dose methotrexate and 32 underwent conservative surgical management (Laparoscopic salpingostomy) according to the inclusion and exclusion criteria. The distribution of patients was studied accord ing to the age, parity, literacy status, presence of risk factors and followed up with serum $\beta$ HCG levels. The success and failure with both the treatments were defined and the patients were followed up till 2 years for fertility outcome.

\section{RESULTS}

Most of the patients were nulliparous (71.4\%), illiterates (77.7\%) and belong to age group 21-25 years (53.9\%). Half of them had prior risk factors (55.5\%) for ectopic pregnancy. Mean $\beta$ HCG levels came down to normal from day 4 after salpingostomy, but there was a consistent fall till day 28 after methotrexate treatment. Complications were seen with both the treatments. The rate of success was comparatively more for salpingostomy patients (84.3\%), but the difference is not statistically significant. The successful patients were followed up for tubal patencies, ectopic pregnancies and recurrent ectopic pregnancies and the differences were not statistically significant with both medical and conservative surgical treatments.

\section{CONCLUSION}

Conservative surgical treatment and medical treatment are both almost equally effective to preserve the subsequent fertility of the women. According to our study, the difference in success and failure for both the treatments (Medical and surgical) and the difference in fertility outcome in 2 years - pregnancy rate and recurrent ectopic with both medical and conservative surgical is not statistically significant. However, for firm conclusion to be drawn randomized multicentric trials have to be done.

\section{KEYWORDS}

Unruptured Ectopic Pregnancy, Methotrexate, Salpingotomy.

HOW TO CITE THIS ARTICLE: Padma Y, Lakshmi G, Suhasini K, et al. Comparative study of medical and conservative surgical methods for unruptured ectopic pregnancies. J. Evolution Med. Dent. Sci. 2016;5(13):588-592, DOI: 10.14260/jemds/2016/134

\section{INTRODUCTION}

There is increased incidence of ectopic pregnancy in the present years due to early diagnosis, popularity of contraception, extensive use of Assisted Reproductive Technology, tubal surgery and due to increased incidence of sexually transmitted diseases. ${ }^{1}$ The incidence of ectopic pregnancy is $2.1 .^{2}$ there is also increased incidence of recurrent ectopic pregnancy.

According to Ankum and Colleagues. ${ }^{3}$ recurrence after one ectopic is about $10 \%$. The incidence of heterotopic pregnancy after ART is about $0.5-1 \%$ according to Mekel and Teal.

Financial or Other, Competing Interest: None.

Submission 28-12-2015, Peer Review 24-01-2016,

Acceptance 30-01-2016, Published 15-02-2016.

Corresponding Author:

Dr. Garuda Lakshmi,

Flat No. 402, Prakruthi Dew Drops Apartment,

Adjacent to Bajaj Electronics, RTC X Roads,

Chikkadapally, Hyderabad, Telangana.

E-mail: garudalakshmi5@gmail.com

DOI:10.14260/jemds/2016/134
The incidence after ZIFT is $4.3 \%$ and after IVF is $1.8 \%$ (SART and ASRM 2007).

In developed countries improvements in the diagnosis and treatment of ectopic pregnancy have shifted concerns from the immediate health of the women towards preserving her subsequent fertility. This is one of the goals of conservative treatment.

Conservative surgical treatment was first advocated by Kelly in 1898. Stromme. ${ }^{4}$ was the first surgeon for successful use of salpingostomy. It is the preferred surgical method when patients desire future fertility. Medical treatment by methotrexate was developed more recently. Tanaka. ${ }^{5}$ and associates were the first to use methotrexate for ectopic pregnancy.

\section{AIM}

To assess the success, safety and future fertility in patients of ectopic pregnancy when managed by conservative methods medical and surgical. 


\section{OBJECTIVE}

To study and compare medical (Methotrexate) versus surgical (Laparoscopic salpingostomy) conservative management for unruptured ectopic pregnancy.

\section{MATERIAL AND METHODS}

This is a prospective study conducted at CKM Government Maternity Hospital, Warangal, Telangana. The recruitment period was from July 2012 to June 2013 and these patients were followed for 2 years from July 2013 to June 2015. An institutional ethical clearance was obtained before starting the study. An informed consent was taken from the patients who were selected for the study.

Sixty three cases of unruptured ectopic pregnancy were diagnosed by transvaginal sonography and serum $\beta$ HCG levels. Medical management with Methotrexate was done in 31 cases and conservative surgical management (Salpingostomy) was done in 32 patients and the success rate for fertility and complications in both groups were compared in the study.

\section{Inclusion Criteria for Medical/Conservative Surgical Management}

- Hemodynamically stable patients.

- Asymptomatic motivated compliant patients.

- Size of ectopic sac $\leq 4 \mathrm{cms}$.

- $\quad$ Cases with or without cardiac activity included.

- Initial $\beta$ HCG levels $5000 \mathrm{mIU} / \mathrm{mL}$.

- Patients who had single/no live child.

Exclusion Criteria for Medical/Conservative Surgical Management

- Acute intraabdominal haemorrhage.

- Hemodynamically unstable women.

- Interstitial pregnancy.

- Initial $\beta$ HCG level $>5000 \mathrm{mIU} / \mathrm{mL}$.

- Size of gestational sac $>4 \mathrm{cms}$.

- Immunodeficiency.

- Chronic hepatic or pulmonary disease.

- Blood dyscrasias.

- Peptic ulcer disease.

The distribution of the patients was studied according to the age, parity, literacy status, previous history of ectopic pregnancy and the results were compared. The presence of risk factors (1 or more), history of primary or secondary infertility and any treatment undertaken for the same were noted. History of prior tubal surgeries were also noted. These patients were monitored after treatment with $\beta$ HCG levels.

Multiple dose regimen of methotrexate was followed for medical management. Methotrexate $1 \mathrm{mg} / \mathrm{kg}$ was given intramuscularly on days $1,3,5,7$ and leucovorin $0.1 \mathrm{mg} / \mathrm{kg}$ was given intramuscularly on days $2,4,6$, 8. Serum $\beta$ HCG levels were monitored on day $1,3,5$, 7. If the decrease is $\geq 15 \%$, then the values were repeated weekly until undetectable. These patients were monitored with weekly hemogram and liver function tests.

After salpingostomy, the values were repeated on day 4 and on day 7 and weekly if decreased values were not obtained. When the $\beta$ HCG levels came down to undetectable levels, the conservative management was considered to be successful.
When the $\beta$ HCG levels were increasing or not declining in spite of giving multiple doses of methotrexate, then those cases were taken as failures. Those cases which ruptured during medical treatment were also taken as failures. Those who were diagnosed to have persistent trophoblastic disease on follow up were also taken as failures.

When salpingostomy was not possible because of hemorrhage during procedure or when $\beta$ HCG levels did not come to normal within 3 weeks after the procedure (Persistent trophoblastic disease), they were considered as failure of conservative management.

Long term follow-up for the successful cases was done to evaluate the fertility by noting number of tubal patencies, intrauterine pregnancies and recurrent ectopic pregnancies.

\section{RESULTS}

Total number of deliveries during recruitment period were 7749. Total number of ectopic pregnancy cases were 242 during the recruitment period. Out of these, 179 cases were ruptured ectopic pregnancies/tubal abortions, which were admitted in emergency ward and treated immediately by laparotomy/operative laparoscopy after improving the general condition. The remaining 63 cases were unruptured ectopic pregnancies, which were taken as cases for the present study (Figure I).

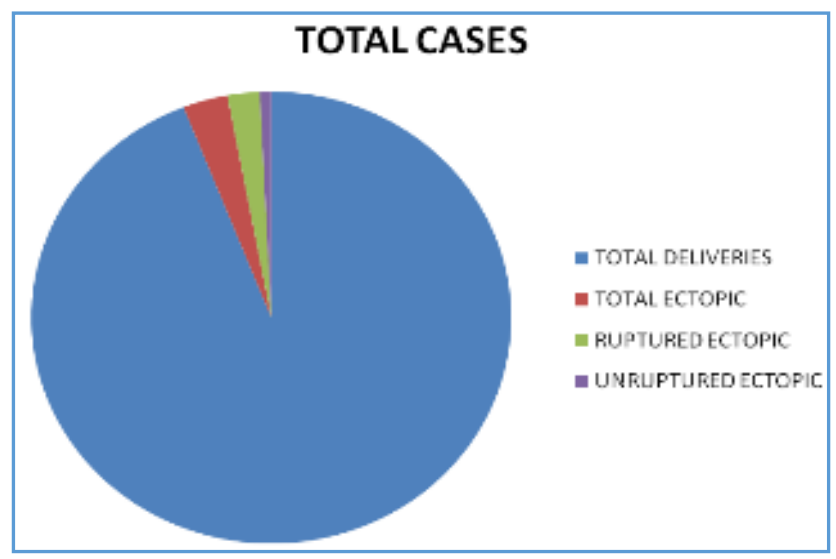

Fig. 1: Total Number of Cases

\begin{tabular}{|c|c|c|}
\hline $\begin{array}{l}\text { AGE IN } \\
\text { YEARS }\end{array}$ & $\begin{array}{c}\text { METHOTREXATE } \\
\mathbf{n = 3 1}(\mathbf{\%})\end{array}$ & $\begin{array}{c}\text { SALPINGOSTOMY } \\
\mathbf{n = 3 2 ( \% )}\end{array}$ \\
\hline $16-20$ & $3(9.6)$ & $2(6.2)$ \\
\hline $21-25$ & $16(51.6)$ & $18(56.2)$ \\
\hline $26-30$ & $10(32.2)$ & $11(35.4)$ \\
\hline $30-35$ & $2(6.4)$ & $1(3.1)$ \\
\hline \multicolumn{2}{|r|}{ Table 1: Distribution of Patients According to Age } \\
\hline
\end{tabular}

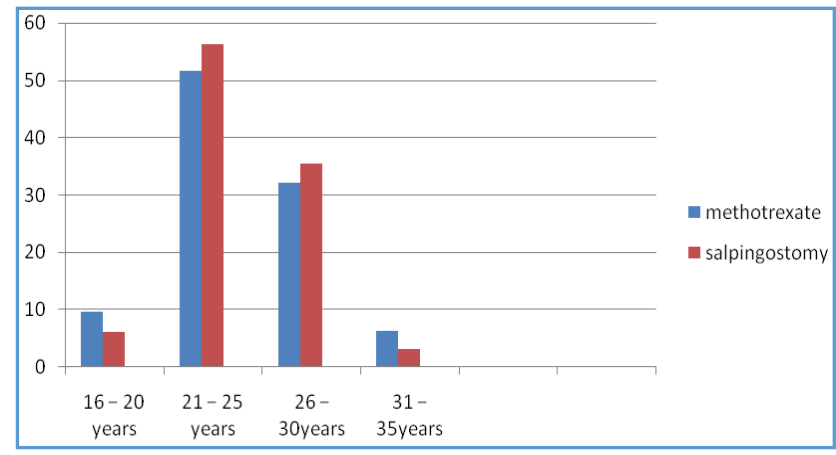

Fig. 2: Distribution of Patients According to Age 


\begin{tabular}{|c|c|c|}
\hline PARITY & $\begin{array}{c}\text { METHOTREXATE } \\
\mathbf{n = 3 1 ( \% )}\end{array}$ & $\begin{array}{c}\text { SALPINGOSTOMY } \\
\mathbf{n = 3 2 ( \% )}\end{array}$ \\
\hline Nulliparous & $23(74.1)$ & $22(68.7)$ \\
\hline 1 Child & $8(25.8)$ & $10(31.2)$ \\
\hline \multicolumn{2}{|c|}{ Table 2: Distribution of Patients According to Parity } \\
\hline
\end{tabular}

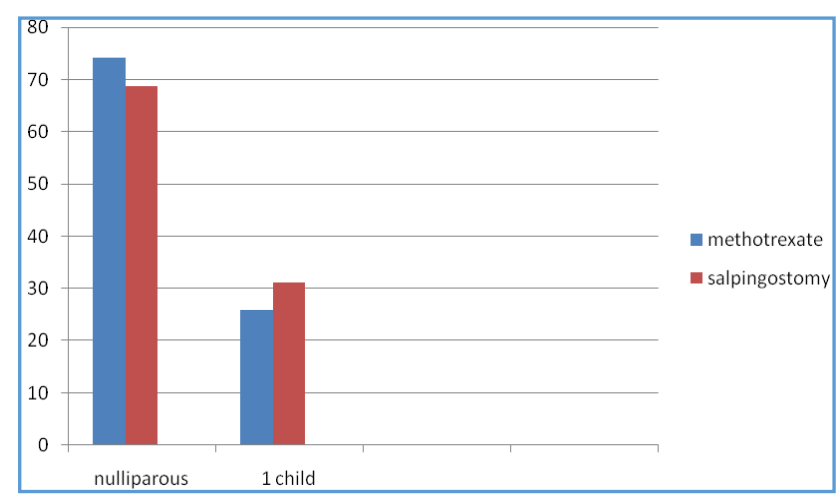

Fig. 3: Distribution of Patients According to Parity

\begin{tabular}{|c|c|c|}
\hline STATUS & $\begin{array}{c}\text { METHOTREXATE } \\
\mathbf{n = 3 1}(\%)\end{array}$ & $\begin{array}{c}\text { SALPINGOSTOMY } \\
\mathbf{n = 3 2 ( \% )}\end{array}$ \\
\hline ILLITERATE & $25(80.6)$ & $24(75.0)$ \\
\hline LITERATE & $6(19.3)$ & $8(25)$ \\
\hline \multicolumn{2}{|c|}{ Table 3: Distribution of Patients } \\
According to Literacy Status \\
\hline
\end{tabular}

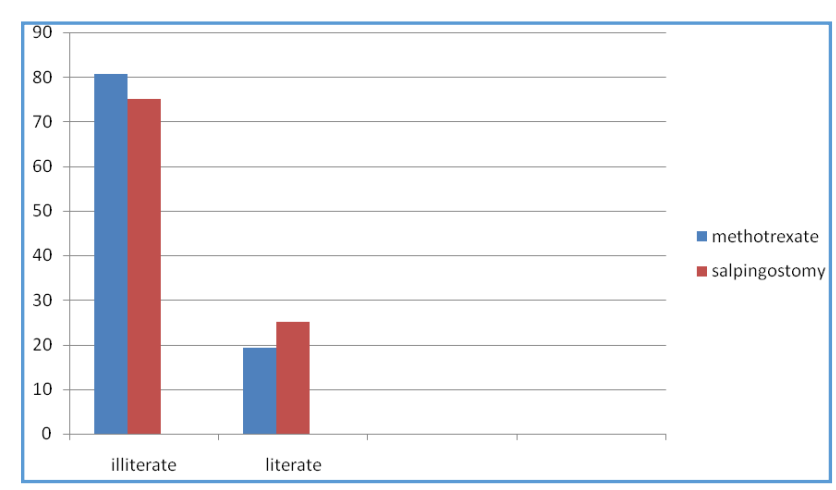

Fig. 4: Distribution of Patients According to Literacy Status

\begin{tabular}{|c|c|c|}
\hline $\begin{array}{c}\text { PREVIOUS } \\
\text { ECTOPIC }\end{array}$ & $\begin{array}{c}\text { METHOTREXATE } \\
\mathbf{n = 3 1}(\mathbf{\%})\end{array}$ & $\begin{array}{c}\text { SALPINGOSTOMY } \\
\mathbf{n = 3 2 ( \% )}\end{array}$ \\
\hline Present & $5(16.2)$ & $6(18.7)$ \\
\hline Absent & $26(83.8)$ & $26(81.3)$ \\
\hline \multicolumn{2}{|c|}{ Table. 4: Previous H/O Ectopic Pregnancy } \\
\hline
\end{tabular}

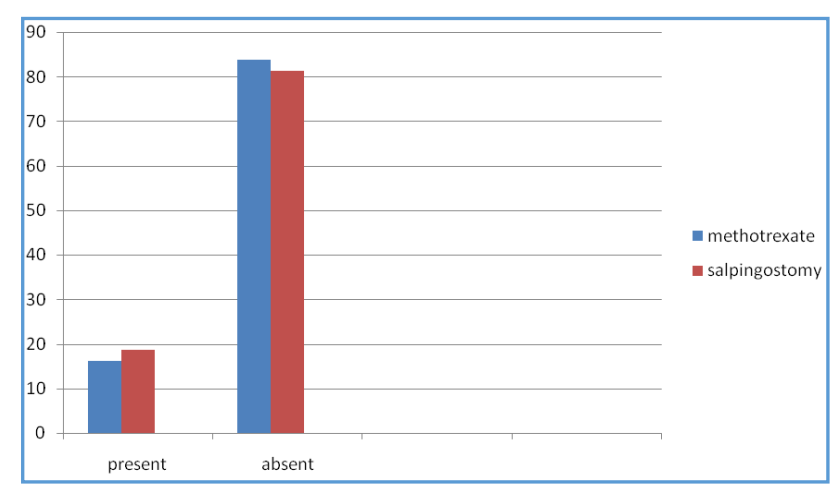

Fig. 5: Previous H/O Ectopic Pregnancy

\begin{tabular}{|c|c|c|}
\hline RISK FACTOR & $\begin{array}{c}\text { METHOTREXATE } \\
\mathbf{n}=31(\%)\end{array}$ & $\begin{array}{c}\text { SALPINGOSTOMY } \\
n=32(\%)\end{array}$ \\
\hline $\begin{array}{l}\text { Induced/spontaneous } \\
\text { abortion }\end{array}$ & $3(9.6)$ & $4(12.5)$ \\
\hline Primary infertility & $7(22.5)$ & $6(18.7)$ \\
\hline Secondary infertility & $2(6.4)$ & $5(15.6)$ \\
\hline Infections/STD & $4(12.9)$ & $3(9.3)$ \\
\hline $\begin{array}{l}\text { Previous tubal } \\
\text { surgery }\end{array}$ & 0 & $1(3.1)$ \\
\hline No risk factors & $15(48.3)$ & $13(40.6)$ \\
\hline
\end{tabular}

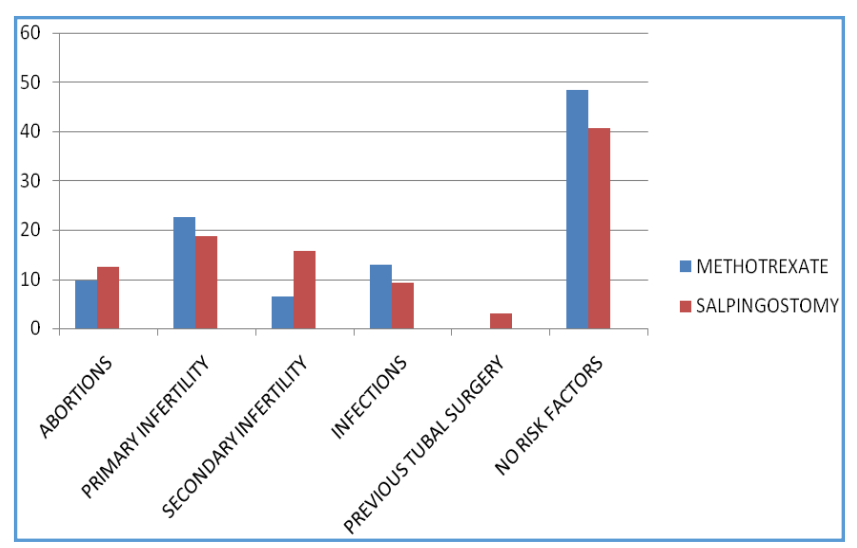

Fig. 6: Comparison of Risk Factors

\begin{tabular}{|c|c|}
\hline SALPINGOSTOMY & 4557 \\
\hline METHOTREXATE & 4632 \\
\hline \multicolumn{2}{|c|}{ Table 6: Mean $\boldsymbol{\beta}$ HCG Levels Before Treatment } \\
\hline
\end{tabular}

\begin{tabular}{|c|c|c|}
\hline DAYS & METHOTREXATE & SALPINGOSTOMY \\
\hline 4 & 3546 & 20 \\
\hline 7 & 1543 & 6 \\
\hline 14 & 732 & 1 \\
\hline 21 & 38 & 0.3 \\
\hline 28 & 5 & \\
\hline 35 & 0.5 & Treatment in \\
\hline \multicolumn{2}{|c|}{ Table 7: Mean $\beta$ HCG Levels after } \\
Both Groups
\end{tabular}

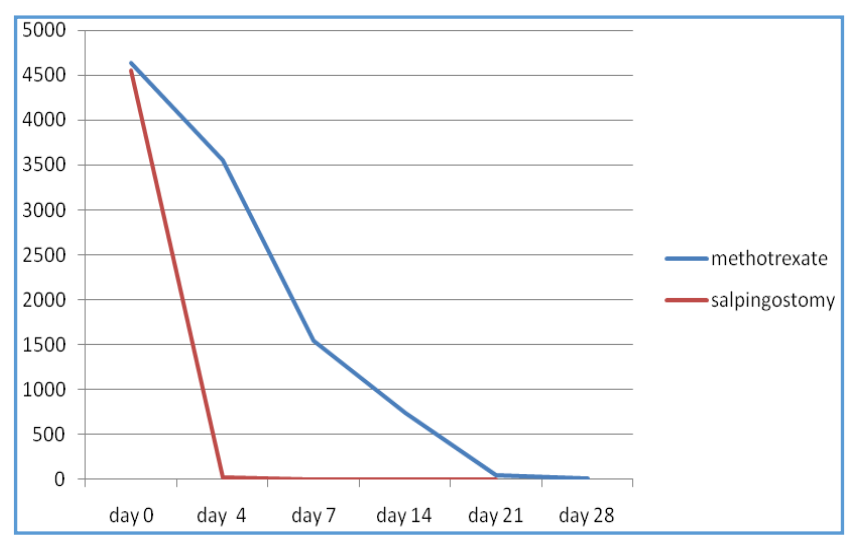

Fig. 7: Mean $\beta$ HCG Levels before and after Treatment 


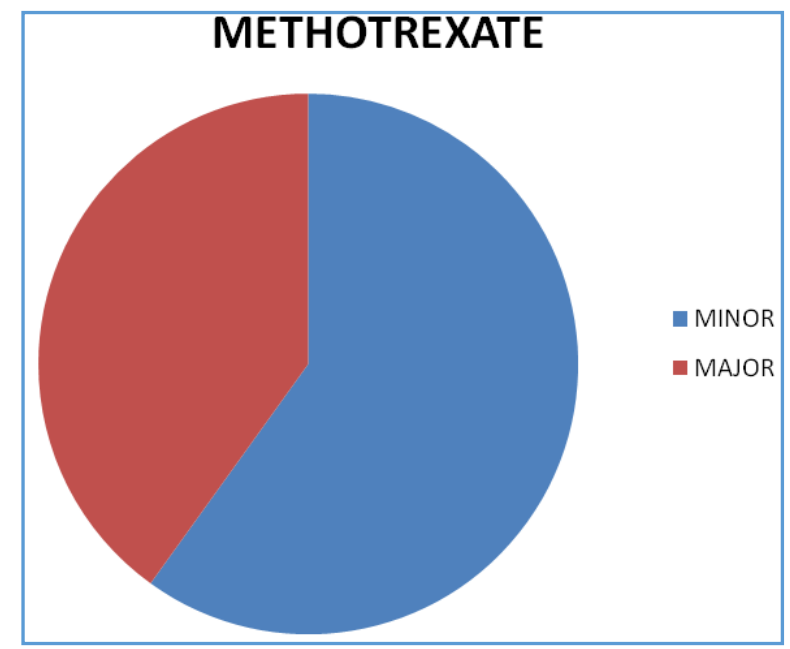

Fig. 8: Complications

Complications were seen with both the groups. Minor complications with methotrexate like stomatitis, alopecia, loss of appetite was seen in 6 cases. Major complications like abdominal pain due to intraperitoneal hemorrhage and leucopenia that led to hospital admission for observation were seen in 4 cases where methotrexate was given; 5 cases needed surgical management because there was no response to multiple doses (Persistent trophoblastic disease) and in 2 cases surgery was done due to rupture.

Hemorrhage was seen as a complication during laparoscopic salpingostomy intraoperatively in 5 cases. Hemostasis was achieved and blood transfusion given in 2 cases, whereas in 3 cases salpingectomy was done to control the hemorrhage; 2 patients were diagnosed to have persistent trophoblastic disease and were subsequently given methotrexate. $(6,7)$

\begin{tabular}{|c|c|c|}
\hline RESULT & $\begin{array}{c}\text { METHOTREXATE } \\
\mathbf{n = 3 1}(\%)\end{array}$ & $\begin{array}{c}\text { SALPINGOSTOMY } \\
\mathbf{n = 3 2 ( \% )}\end{array}$ \\
\hline SUCCESS & $24(77.4)$ & $27(84.3)$ \\
\hline FAILURE & $7(22.5)$ & $5(15.6)$ \\
\hline \multicolumn{2}{|c|}{ Table 8: Comparison of the Results of the Treatment } \\
\hline
\end{tabular}

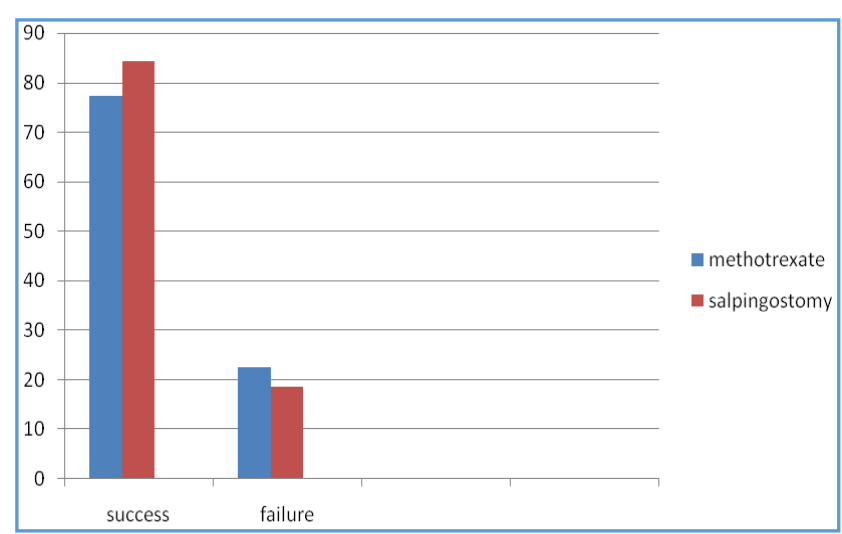

Fig. 9: Comparison of the Results of Treatment

Among the successful cases after salpingostomy (29), 3 cases were lost for followup. In the methotrexate group, 2 cases were lost for followup. These patients were followed up for the future fertility outcome.

\begin{tabular}{|c|c|c|}
\hline OUTCOME & $\begin{array}{c}\text { METHOTREXATE } \\
\mathbf{n = 2 0}(\%)\end{array}$ & $\begin{array}{c}\text { SALPINGOSTOMY } \\
\mathbf{n = 2 3 ( \% )}\end{array}$ \\
\hline $\begin{array}{c}\text { TUBAL } \\
\text { PATENCY }\end{array}$ & $14(70)$ & $18(78.2)$ \\
\hline $\begin{array}{c}\text { PREGNANCY } \\
\text { RATE }\end{array}$ & $12(60)$ & $14(60.8)$ \\
\hline $\begin{array}{c}\text { REPEAT } \\
\text { ECTOPIC }\end{array}$ & $3(9.6)$ & $4(12.5)$ \\
\hline \multicolumn{2}{|c|}{ Table 9: Fertility Outcome } \\
\hline
\end{tabular}

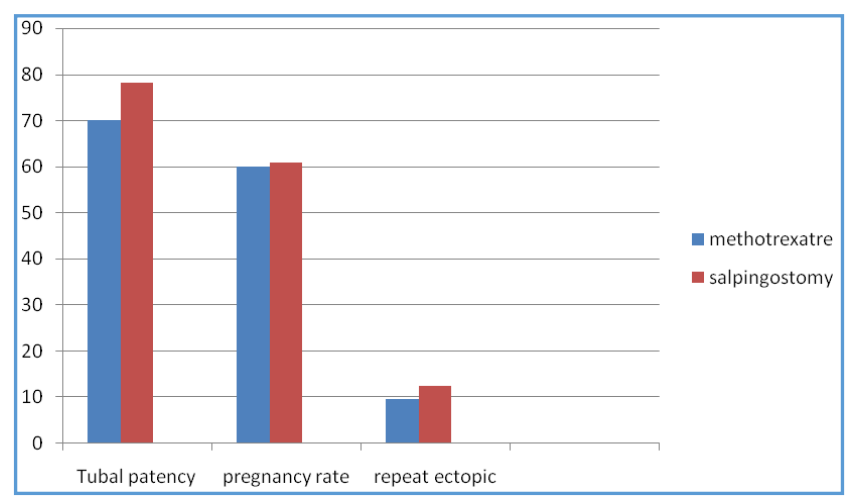

Fig. 10: Fertility Outcome

\section{DISCUSSION}

In our study, majority of the patients were in the age group of 21-25 years in both groups. Most of the patients are nulliparous with $20.6 \%$ incidence of primary infertility in these patients.

In Hemodynamically stable patients with unruptured tubal pregnancy, systemic methotrexate and laparoscopic salpingostomy were successful in treatment of majority of the cases.

The average methotrexate resolution rate among the study included was $77.4 \%$. Of the 63 patients who were included in the trial, 31 patients were allocated systemic methotrexate of whom salpingectomy was necessary in $6.4 \%$ of these patients for tubal rupture.

of 32 patients allocated laparoscopic salpingostomy, $6.2 \%$ needed methotrexate for persistent trophoblast and there was no case of tubal rupture noted.

The rate of failure of conservative surgical treatment $(15.6 \%)$ was lower than that reported in other studies. The failure rate of medical treatment $(22.5 \%)$ was consistent with that reported in some studies. ${ }^{8-11}$

In our study comparing fertility after medical and conservative surgical treatment showed that reproductive performance was slightly better with salpingostomy than that of medical management. This may be because of persistence of mass for a long period that may impair tubal patency and future fertility. Most other studies found little or no difference.(1,12-15) Lipscomb and Associates found no difference of fertility outcome either with Methotrexate of Salpingostomy. ${ }^{16}$ The sample size in the present study may be too small for conclusion to be drawn.

In the study done by Fernandez et al. ${ }^{9}$ comparing fertility after medical and conservative surgical treatment showed that spontaneous reproductive outcome was similar in both groups. During follow-up after 6 months of treatment tubal patency was assessed in both groups. The tube was patent in $45.1 \%$ of 31 patients in the methotrexate group and in $56.2 \%$ of 32 patients in the salpingostomy group. 
In our study, the overall 2-year cumulative rate of recurrent ectopic pregnancy was $16.2 \%$. The overall 2 -year cumulative rate of recurrent ectopic pregnancy was same with conservative surgery or medical therapy.

\begin{tabular}{|c|c|c|c|}
\hline STUDY & $\begin{array}{c}\text { TUBAL } \\
\text { PATENCY }\end{array}$ & $\begin{array}{c}\text { INTRAUTERINE } \\
\text { PREGNANCY }\end{array}$ & $\begin{array}{c}\text { REPEAT } \\
\text { ECTOPIC }\end{array}$ \\
\hline $\begin{array}{c}\text { Buster and } \\
\text { Krotz study } \\
2007\end{array}$ & $75-81 \%$ & $52-61 \%$ & $8-13 \%$ \\
\hline $\begin{array}{c}\text { Present study } \\
2015\end{array}$ & $70-79 \%$ & $60-61 \%$ & $9-13 \%$ \\
\hline \multicolumn{3}{|c|}{$\begin{array}{c}\text { Table 10: } \text { Comparison of Fertility } \\
\text { Outcome with Other Studies }\end{array}$} \\
\hline
\end{tabular}

Buster and Krotz. ${ }^{17}$ study showed that there is no difference in tubal patency (75-81\%), intrauterine pregnancy (52-61\%) or recurrent ectopic pregnancy $(8-13 \%)$ treated with either laparoscopic salpingostomy or with methotrexate.

Stovall and Colleagues. ${ }^{18}$ used single dose methotrexate $50 \mathrm{mg} / \mathrm{m}^{2}$ and found complete resolution (94.2\%), mean time of resolution (35.5 days); 3.5\% needed second course of methotrexate on day 7 and laparotomy in $5.8 \%$. Tubal patency with HSG was seen in $82.3 \%$ cases.

Rates of intrauterine pregnancy were significantly higher if the contralateral tube was normal, lower if the woman was older or had a history of infertility.

Salpingostomy is a conservative surgical procedure, which requires expertise and the initial cost is more. The medical management with methotrexate requires long-term followup with serum $\beta$ HCG levels. Also it may require frequent readmissions and laparotomy in case of persisting levels, which might increase the overall cost. 19

\section{CONCLUSION}

Conservative surgical treatment and medical treatment are both almost equally effective to preserve the subsequent fertility of the women. According to our study, the difference in success and failure for both the treatments (Medical and surgical) was not statistically significant. The difference in fertility outcome in 2 years - pregnancy rate and recurrent ectopic with both medical and conservative surgical is not statistically significant. However, for firm conclusion to be drawn randomized multicentric trials have to be done.

\section{REFERENCES}

1. Fertility following radical, conservative surgical and medical treatment for tubal pregnancy: a population based study, BJOG: June 2000, vol 7:6;714-21.

2. Cunningham F, Kennath Leveno, Steven Bloom, et al. Role and criteria of methotrexate in unruptured ectopic pregnancy, Williams Obstetrics, 23rd edition, Page: 246251.

3. Coste J, Job Spira N, Aublet Cuvelier Betal. Incidence of ectopic pregnancy. First results of a population based register in France. Human Reprod 1994;9:742-45.
4. Ronald S Gibbs, Beth Y Karlan, Arthur F Haney, et al. Medical management with methotrexate vs surgical management by salpingostomy, Danforth's textbook of Obstetrics and Gynecology, 10 $0^{\text {th }}$ Edition, 2008 April, Page 81.

5. Tanaka T, Hayashi H, Kutsuzawa T, et al. Treatment of interstitial ectopic pregnancy with methotrexate: report of a successful case. Fertil Steril 1982;37:851-852.

6. Lundorff $\mathrm{P}$, Hahlin $\mathrm{M}$, Sjoblom $\mathrm{P}$, et al. Persistent trophoblast after conservative treatment of tubal pregnancy; prediction and detection. Obstet Gynecol 1991;77:129-33.

7. Graczy Kowski JW, Mishell D. Methotrexate prophylaxis for persistent ectopic pregnancy after conservative treatment by salpingostomy. Obstet Gynecol 1997;89:118-22.

8. Valle JS, Lifchez AS. Reproductive outcome following conservative surgery for tubal pregnancy in women with a single fallopian tube. Fert Ster 1983;39:164-66.

9. Stabile I. Ectopic pregnancy diagnosis and management, Cambridge. Cambridge University Press, 1996.

10. Bruhat HA, Mahes H, Mage G, et al. Treatment of ectopic pregnancies by laparoscopy. Fert Ster 1980;33:411-14.

11. Fernandez H, Capella Allouc S, Vincent Y, et al. Randomized trial of conservative laparoscopic treatment and methotrexate administration in ectopic pregnancy and subsequent fertility. Human Reprod 1998; 13:3239-43.

12. Mol F, Mol BW, Ankum WM, et al. Current evidence on surgery, systemic methotrexate and expectant management in the treatment of tubal ectopic pregnancy: a systematic review and meta-analysis. Human reproduction update 2008 July-August; 14(4):309-319.

13. Hajenius PJ, Engelsbel S, Mol BWJ. Randomized trial of systemic methotrexate versus salpingostomy in tubal pregnancy. Lancet 1997;350:774-79.

14. Nieuwkerk PT, Hajenius PJ, Van Der Veen F, et al. Systemic methotrexate therapy versus laparoscopic salpingostomy in tubal pregnancy. Part II - Patient preferences for systemic methotrexate. Fert Ster 1998; 70:518-22.

15. Mr AJ Kelly, Dr MC Sowter, Dr J Trinder. Management of tubal pregnancy. RCOG Guideline No. 21, 2004.

16. Lipscomb GH, Bran D, McCord ML, et al. Analysis of 315 ectopic pregnancies treated with single-dose methotrexate. Am J Obstet Gynecol 1998;178:1354-58.

17. Buster JE, Krotz S. Reproductive performance after ectopic pregnancy. Sem Reprod Med 25:131, 2007.

18. Stovall TG, Ling FW. Single-dose methotrexate - an expanded clinical trial. Am J Obstet Gynecol 1993; 168:1759-62.

19. Morlock RJ, Lafata JE, Eisenstein D. Cost effectiveness of single-dose methotrexate compared with laparoscopic treatment of ectopic pregnancy, Obstet Gynecol 2000 March; 95(3): Page 407-412. 